\title{
DESEMPENHO DE CROTALÁRIA CONSORCIADA COM MILHETO NA PRODUÇÃO DE BIOMASSA ${ }^{1}$
}

\author{
Karina Mendes Bertolino \\ Giuliana Rayane Barbosa Duarte \\ Gustavo Maldini Penna de Valadares e Vasconcelos \\ Élberis Pereira Botrel
}

\begin{abstract}
RESUMO
O objetivo deste estudo foi avaliar o desempenho da crotalária e milheto consorciados em diferentes proporções, bem como a melhor época de manejo e a combinação de consórcio para a produção de palhada. O delineamento utilizado foi o de blocos casualizados em esquema de parcela subdividida, sendo as parcelas constituídas de crotalária (Crotalaria spectabilis) (CR) e milheto (Pennisetum glaucum (L.) (MI) consorciados em diferentes proporções $(100 \%$ CR; $80 \% \mathrm{CR}+20 \% \mathrm{MI} ; 60 \% \mathrm{CR}+40 \% \mathrm{MI} ; 40 \% \mathrm{CR}+60 \% \mathrm{MI} ; 100 \% \mathrm{MI})$ e as subparcelas duas épocas de manejo (86 e 118 dias após a semeadura), com quatro repetições. No qual tiveram como variável resposta a altura de plantas e a biomassa seca. O índice de eficiência e uso da terra foi calculado por meio dos dados obtidos de massa seca total dos consórcios aos 118 dias após a semeadura. A melhor época para o manejo das plantas em consórcio foi aos 118 dias após a semeadura, onde se obteve a quantidade suficiente de massa seca para cobertura do solo sob sistema de plantio direto. O consórcio mais vantajoso em termos agronômicos foi o constituído por $20 \%$ CR $+80 \%$ MI.
\end{abstract}

Palavras-chave: Palhada. Crotalaria spectabilis. Pennisetum glaucum (L.).

\section{Crotalary performance consortiated with millet in biomass production}

\begin{abstract}
The objective of this study was to evaluate the performance of intercropped crotalary and millet in different proportions, as well as the best management time and the combination of intercropping for the production of straw. The design used was that of randomized blocks in a subdivided plot scheme, with plots consisting of crotalary (Crotalaria spectabilis) (CR) and millet (Pennisetum glaucum (L.)) (MI) intercropped in different proportions (100\% CR; $80 \%$ $\mathrm{CR}+20 \% \mathrm{MI} ; 60 \% \mathrm{CR}+40 \% \mathrm{MI} ; 40 \% \mathrm{CR}+60 \% \mathrm{MI} ; 100 \% \mathrm{MI})$ and the subplots two management times (86 and 118 days after sowing), with four replications. In which the height of plants and dry biomass were the variable response. The efficiency and land use index were calculated using data obtained from the total dry mass of the consortia at 118 days after sowing. The best time for the management of the intercropped plants was 118 days after sowing, where sufficient dry mass was obtained to cover the soil under no-tillage system. The most advantageous consortium in agronomic terms was the one constituted by $20 \% \mathrm{CR}+80 \% \mathrm{MI}$.
\end{abstract}

\footnotetext{
${ }^{1}$ Como citar este artigo: BERTOLINO, K. M. et al. Desempenho de crotalária consorciada com milheto na produção de biomassa. ForScience, Formiga, v. 9, n. 1, e00895, jan./jun. 2021. DOI: 10.29069/forscience.2021v9n1.e895.

${ }^{2}$ Autor para correspondência: Karina Mendes Bertolino, e-mail: karina.bertolino@yahoo.com.br.
} 
Keywords: Straw. Crotalaria spectabilis. Pennisetum glaucum (L.)

\section{INTRODUÇÃO}

A redução do potencial de produção de solos de regiões tropicais e subtropicais está relacionada, sobretudo, com a erosão hídrica e redução da matéria orgânica. A utilização de técnicas que empregam o cultivo mínimo e a adição de matéria orgânica por meio do uso de plantas de cobertura se torna uma opção indispensável para a estruturação química, física e biológica do solo (MARCATE; CAMACHO; PAREDES, 2011).

As plantas de cobertura e/ou adubos verdes são plantas utilizadas para formação de palhada e incorporação ou reciclagem de nutrientes no solo. Assim, essas espécies propiciam melhoria nas propriedades do solo, aumentando a matéria orgânica e consequentemente amenizando a erosão hídrica ou eólica devido a proteção proporcionada pela cobertura morta. Essa cobertura promove também a manutenção da temperatura do solo, além de servir como barreira física contra a germinação de plantas daninhas (BOER et al., 2008).

O milheto (Pennisetum glaucum (L.) é uma planta de cobertura muito utilizada para formação de palhada e cobertura do solo, por ser considerada pouco exigente em fertilidade, tendo assim boa adaptação em diferentes regiões, sobretudo com solos pobres, com ocorrência de déficit hídrico e altas temperaturas. Essa planta possui sistema radicular vigoroso e eficiente em absorção de nutrientes, sendo essa uma das principais características que fazem do milheto uma planta de destaque dentre as outras utilizadas como cobertura do solo (MARCATE; CAMACHO; PAREDES, 2011). Já a crotalária (Crotalaria spectabilis) é uma leguminosa que tem como principais características, a associação simbiótica com bactérias fixadoras de nitrogênio e a baixa relação $\mathrm{C} / \mathrm{N}$, o que resulta em rápida decomposição dos seus resíduos, assegurando o suprimento de nutrientes das culturas posteriores (PERIN et al., 2010).

O consórcio é o cultivo simultâneo de duas ou mais espécies em uma mesma área, sendo essa prática comum entre os agricultores de regiões tropicais por possuir vantagens como o melhor aproveitamento dos recursos disponíveis tais como água, luz e nutrientes (BEZERRA et al., 2007). A associação entre gramíneas e leguminosas propicia benefícios aos sistemas de produção, uma vez que essas plantas apresentam características distintas, resultando em exploração de diferentes camadas de solo, promovendo a ciclagem diferenciada dos nutrientes (CHERR; SCHOLBERG; MCSORLEY, 2006). Outra vantagem é produção de biomassa seca com relação $\mathrm{C} / \mathrm{N}$ intermediária, promovendo assim a menor taxa de decomposição dos resíduos. Assim sendo, torna-se de grande relevância o estudo do comportamento e desempenho das espécies utilizadas nesse tipo de consórcio (CARVALHO et al., 2013). 
O consórcio entre plantas de cobertura, especialmente gramíneas e leguminosas tem sido estudado por diversos pesquisadores. Ferrari Neto et al. (2011), em um de seus trabalhos sobre plantas de cobertura, manejo da palhada e produtividade da mamoneira (Ricinus communis L.) o sistema plantio direto, constatou que o milheto produziu mais biomassa seca em monocultivo que quando cultivado em consórcio com outra leguminosa. Contudo, outros trabalhos mostram que embora o milheto tenha um rápido crescimento nos primeiros dias após a semeadura, dominando sobre leguminosas como o guandu anão (Cajanus cajan (L.) Millsp.), essa gramínea produz maior fitomassa quando consorciada se comparada ao monocultivo (CALVO; FOLONI; BRANCALIÃO, 2010).

A eficiência dos consórcios é em grande parte dependente da complementariedade entre as culturas. A complementariedade temporal ocorre quando as plantas envolvidas no consórcio demandam por recursos ambientais em períodos distintos e com isso a competição pode ser minimizada. Por outro lado, a complementaridade espacial ocorre quando a diferença na arquitetura da planta favorece a melhor utilização de água, luz e nutrientes disponíveis. A complementariedade temporal é o principal fator determinante da eficiência em consórcios (WILLEY, 1979). Portanto, para verificar a eficiência do consórcio, ou seja, se o consórcio é mais produtivo que o monocultivo, pode-se adotar o índice de Uso de Eficiência da Terra (IEA) (RÓS; SÃO JOÃO, 2016) ou Índice de Equivalência de Área (IEA), que evidencia que um consórcio tem maior produtividade que o monocultivo das espécies constituintes sempre que o valor do índice for maior que 1 (IEA>1) (LIEBMAN, 2012).

Diante do exposto, o objetivo desse estudo foi avaliar o desempenho da Crotalaria spectabilis e do Pennisetum glaucum (L.) consorciadas em diferentes proporções, bem como a melhor época de manejo e combinação de consórcio para a produção de palhada para os sistemas de produção de grãos.

\section{MATERIAL E MÉTODOS}

O experimento foi instalado na área experimental do Departamento de Agricultura (DAG) da Universidade Federal de Lavras (UFLA), em Lavras/MG, com coordenadas geográficas $21^{\circ} 14^{\prime} \mathrm{S}$ e $45^{\circ} 00^{\prime} \mathrm{W}$ e altitude média de 920 metros. O clima da região é classificado como temperado úmido (Cwa) de acordo com Köppen, com inverno seco e chuvas predominantes no verão, com precipitação média anual de $1530 \mathrm{~mm}$ e temperatura média anual de 19,4 ${ }^{\circ} \mathrm{C}$ (BRASIL, 1992; DANTAS; CARVALHO; FERREIRA, 2007). O solo da área experimental é classificado como Latossolo Vermelho Distroférrico Típico (LVDT) 
(EMBRAPA, 1999). Os dados de precipitação pluvial e temperaturas ocorridas no período de dezembro de 2017 a abril de 2018 obtidos pela estação climatológica principal de Lavras localizada no Campus da UFLA, pertencente à rede de observações meteorológicas de superfície do Instituto Nacional de Meteorologia/INMET, estão representadas na Figura 1.

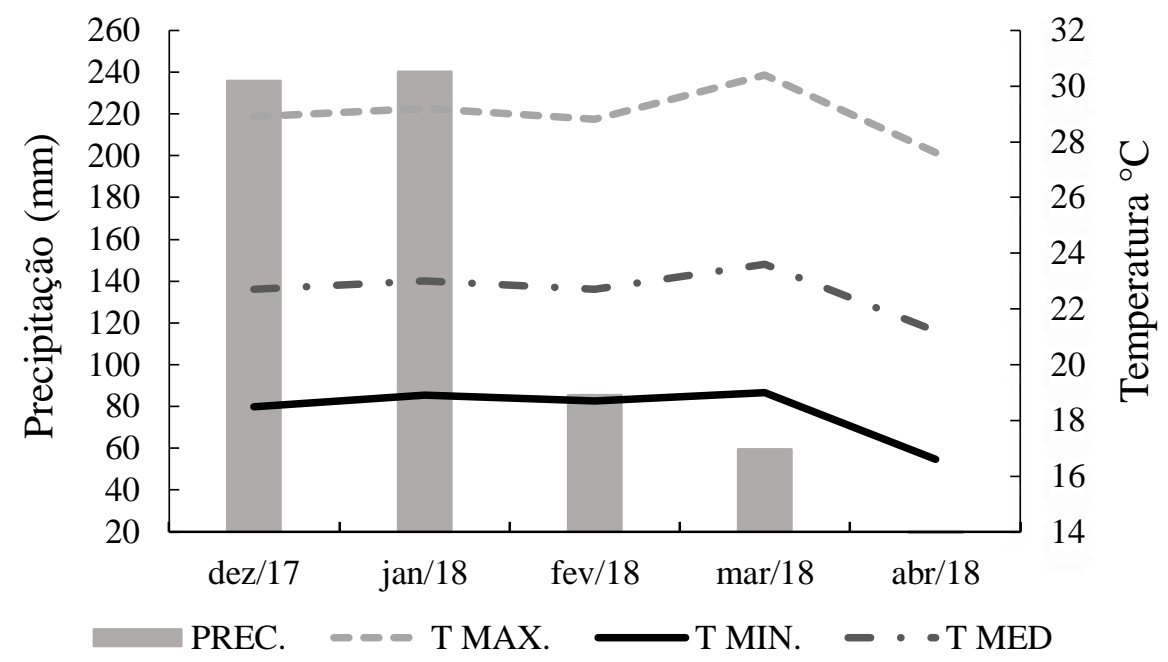

Figura 1 - Precipitação pluvial (PREC, mm) total e temperaturas $\left({ }^{\circ} \mathrm{C}\right)$ mínimas (T MIN.), médias (T MED) e máximas (T MAX.) no período de dezembro de 2017 a abril de 2018 em Lavras/MG

A análise química do solo anterior a instalação do experimento apresentou as seguintes características na camada de 0- 0,20 m: $\mathrm{pH} \mathrm{H}_{2} 0: 6,85 ; \mathrm{Ca}^{2+}: 1,1 \mathrm{cmol} \mathrm{dm}^{-3}, \mathrm{Mg}^{2+}: 0,4 \mathrm{cmol} \mathrm{dm}^{-}$ 3. $\mathrm{Al}^{3+}: 0,1 \mathrm{cmol} \mathrm{dm}^{-3} ; \mathrm{H}+\mathrm{Al}: 2,7 \mathrm{cmol} \mathrm{dm}^{-3}$; Soma de Bases: $1,8 \mathrm{cmol} \mathrm{dm}^{-3}$; CTC efetiva (t): 1,9 $\mathrm{cmol} \mathrm{dm}^{-3}$; CTC a pH 7 (T): 4,5 $\mathrm{cmol} \mathrm{dm}^{-3}$; P (Melhic-1): 12,5 $\mathrm{mg} \mathrm{dm}^{-3} ; \mathrm{K}^{+}: 110,8 \mathrm{mg} \mathrm{dm}^{-}$ 3. Saturação por Bases: 39,6\%; Matéria Orgânica: 2,06 dag kg-1. Argila: 37 dag kg-1$^{-1}$; Silte: 13 dag $\mathrm{kg}^{-1}$; Areia: 50 dag $\mathrm{kg}^{-1}$.

O delineamento experimental utilizado foi o de blocos casualizados (DBC), em esquema de parcela subdividida no tempo com quatro repetições, sendo a parcela constituída de seis proporções de plantas de coberturas consorciadas entre si, totalizando seis tratamentos com quatro repetições. A parcela experimental foi formada por 10 linhas de 4 metros de comprimento, espaçadas de 0,30 metros ente si, totalizando $12,0 \mathrm{~m}^{2}$, com uma área útil de 7,2 $\mathrm{m}^{2}$. Para a determinação da parcela útil, eliminaram-se as duas linhas laterais e 0,5 metros de cada extremidade e as subparcelas foram constituídas de duas épocas de manejo, sendo a primeira no florescimento do milheto (86 dias após a semeadura - DAS) e a segunda no florescimento da crotalária (118 DAS).

O experimento foi instalado em campo em novembro de 2017, sendo que para o preparo do solo foi realizada uma aração e duas gradagens. Antes da última gradagem foi realizada a 
calagem utilizando $1,31 \mathrm{t} \mathrm{ha}^{-1}$ de acordo com a análise de solo. Na sequência procedeu-se a abertura dos sulcos espaçadas de 0,30 m de forma mecanizada para delimitação das parcelas.

As plantas de cobertura foram semeadas simultaneamente e manualmente no sulco de plantio, utilizando-se para a crotalária (CR) (Crotalaria spectabilis) cultivar "comum" a quantidade de $20 \mathrm{~kg} \mathrm{ha}^{-1}$ de sementes para a proporção de $100 \%$ e, para o milheto (MI) (Pennisetum glaucum) cultivar BRS1501, $25 \mathrm{~kg} \mathrm{ha}^{-1}$ de sementes para a proporção de 100\%, ambos da Piraí Sementes. Posteriormente foram calculadas e semeadas a quantidade de semente de acordo com os demais tratamentos constituídos com diferentes proporções de milheto e crotalária: $100 \%$ CR; $80 \%$ CR+ 20\% MI; $60 \%$ CR + 40\% MI; 40\% CR + 60\% MI; $20 \% \mathrm{CR}+$ $80 \%$ MI; 100\% MI. Na ocasião da semeadura não foram realizadas adubações. Aos 35 dias após a semeadura foi realizada a capina manual para o controle de plantas daninhas.

Para a determinação da altura de plantas foram escolhidas aleatoriamente dez plantas de cada espécie em cada parcela e medidas com o auxílio de uma régua graduada partindo-se do colo da planta até seu ápice. A biomassa seca foi obtida a partir da colheita manual de plantas em duas linhas centrais de três metros, as quais pesadas em campo retiraram-se uma amostra de 500 gramas que posteriormente foram secas em estufa de circulação forçada de ar a $65{ }^{\circ} \mathrm{C}$, até atingirem peso constante.

Para o cálculo do Índice de Uso e Eficiência da Terra (IEA) utilizou-se a fórmula sugerida por Willey (1979): IEA $=\mathrm{Y}_{\mathrm{MC}} / \mathrm{Y}_{\mathrm{MM}}+\mathrm{Y}_{\mathrm{CC}} / \mathrm{Y}_{\mathrm{CM}}$, em que: IEA=índice de Uso e Eficiência da Terra, $\mathrm{Y}_{\mathrm{MC}}=$ rendimento do milheto em consórcio, $\mathrm{Y}_{\mathrm{MM}}=$ rendimento do milheto em solteiro; $\mathrm{Y}_{\mathrm{CC}}=$ rendimento da crotalária em consórcio, $\mathrm{Y}_{\mathrm{CM}}=$ rendimento da crotalária em solteiro. Assim: $\left(\mathrm{Y}_{\mathrm{MC}} / \mathrm{Y}_{\mathrm{MM}}\right)=\mathrm{I}_{\mathrm{M}}$ : uso eficiente de terra parcial do milheto e $\left(\mathrm{Y}_{\mathrm{CC}} / \mathrm{Y}_{\mathrm{CM}}\right)=\mathrm{I}_{\mathrm{C}}$ : uso eficiente de terra parcial da crotalária.

Dessa forma, o consórcio será considerado mais eficiente que o cultivo solteiro quando o valor da UET for maior que um (1). Já a contribuição relativa das culturas (CRC) ao UET, provém da razão entre a produtividade relativa individual e o UET total do sistema, indicando o percentual de participação de cada cultura na obtenção do índice total, onde $\mathrm{CRC}_{\mathrm{M}}$ corresponde contribuição relativa do milheto e $\mathrm{CRC}_{\mathrm{C}}$ corresponde a contribuição relativa da crotalária.

A eficiência parcial para cada cultura $\left(\mathrm{ERP}_{\mathrm{M}}\right.$ e $\left.\mathrm{ERP}_{\mathrm{C}}\right)$ foi calculada a partir dos dados das produtividades relativas individuais $\left(\mathrm{I}_{\mathrm{M}}\right.$ e $\left.\mathrm{I}_{\mathrm{C}}\right)$. Esses índices mostram o quanto da produtividade parcial representa em relação à proporção da população para cada cultura. Índices maiores que 1,0 representam ganhos de eficiência para a cultura, quando no estabelecimento daquela combinação de consórcio (SOUZA; MACEDO, 2007). Utilizou-se as fórmulas $\mathrm{ERP}_{\mathrm{M}}=$ 
$\mathrm{I}_{\mathrm{M}} / \mathrm{X}_{\mathrm{M}}$ e $\mathrm{ERP} \mathrm{P}_{\mathrm{C}}=\mathrm{I}_{\mathrm{C}} / \mathrm{X}_{\mathrm{C}}$; onde $\mathrm{ERP}=$ eficiência parcial para cada cultura, $\mathrm{X}_{\mathrm{M}}=$ proporção do milheto na população, $X_{C}=$ proporção da crotalária na população. Para o cálculo dos referidos índices foi utilizada a biomassa seca das plantas de cobertura obtidas no segundo corte, ou seja, 118 DAS.

Os dados obtidos de biomassa seca e altura de plantas (variáveis respostas) foram submetidos a análise de variância (Teste F), que permitiu avaliar os efeitos das proporções de semeio de plantas de cobertura (parcelas) e dos períodos de corte/ avaliação (subparcelas), bem como a interação entre esses fatores. Quando significativas, as médias dos tratamentos foram submetidas à análise de regressão e as médias das épocas comparadas pelo teste de Tukey a 5\% de significância utilizando o programa estatístico Sisvar versão 5.6 (FERREIRA, 2011).

\section{RESULTADOS E DISCUSSÃO}

Analisando somente a altura da CR nas diferentes proporções de semeadura e épocas de manejo, não houve interação significativa (p-valor $=0,07$ ). Para os fatores isoladamente, somente a época teve diferença mínima significativa ( $\mathrm{p}$-valor $=0,02$ ), sendo a altura aos 118 DAS superior aos 86 DAS (Tabela 1).

Tabela 1 - Altura da crotalária (CR) em metros (m) aos 86 e 118 dias após a semeadura (DAS)

\begin{tabular}{cc}
\hline Época (DAS) & Altura CR (m) \\
\hline 86 & $1,12 \mathrm{~b}$ \\
118 & $1,45 \mathrm{a}$ \\
\hline
\end{tabular}

*Médias seguidas pela mesma letra na coluna não diferem entre si pelo teste de Tukey a 5\%

A altura das plantas de crotalária aos 86 DAS foi superior à verificada por Teodoro et al. (2011) que obtiveram para a mesma espécie desse estudo 0,77 cm, também no estágio vegetativo da leguminosa, porém aos 60 dias de cultivo em um Latossolo Vermelho-Amarelo Distrófico no Alto Vale do Jequitinhonha/MG. Contudo, a média da altura nesse estudo foi próxima a observada por Soares et al. (2015), que encontraram em seu trabalho 1,08 m aos 90 DAS em um Latossolo Vermelho Distroférrico no município de Tangará da Serra/MT. Apesar de ter alcançado altura superior a encontrada por outros autores, mesmo sem ter atingido o florescimento, que ocorreu aos 118 DAS, as médias de altura observadas aos 86 DAS para a crotalária estão de acordo com os descritos por Barreto e Fernandes (2001), que relataram que a C. spectabilis é uma planta de porte mediano, alcançando entre 0,60 e 1,50 m de altura. 
Os valores de altura aos 118 DAS, embora sejam maiores que aos 86 DAS, ainda estão de acordo ao encontrado por outros autores como Mateus e Wutke (2006) que descreveram para essa mesma espécie de crotalária, uma planta de crescimento determinando podendo alcançar até seu florescimento entre 1,0 e 1,50 m de altura. De acordo com Teodoro et al. (2011) que avaliando aspectos agronômicos de leguminosas para adubação verde no Alto Vale do Jequitinhonha, observaram que a crotalária se comporta de forma diferente de outras plantas de cobertura, mantendo sua taxa de crescimento praticamente constante até o período de florescimento, que ocorreu aos 92 DAS. Os resultados obtidos para essa característica em duas épocas neste trabalho evidenciaram que o corte precoce, aos 86 DAS, ocasiona perda de produtividade visto que a espécie continua a acumular biomassa seca até seu florescimento.

Neste momento analisando de forma separada o milheto, foi verificada interação significativa entre épocas de corte e proporções de semeadura ( $\mathrm{p}$-valor $=0,01)$. Verificando os desdobramentos dos graus de liberdade das épocas dentro de cada proporção, só houve diferença significativa para a proporção de $40 \% \mathrm{CR}+60 \% \mathrm{MI}$ ( $\mathrm{p}$-valor $=0,02)$, sendo a maior altura encontrada aos 118 DAS (Tabela 2).

Tabela 2 - Altura das plantas de milheto em metros (m) para as proporções estudadas aos 86 e 118 dias após a semeadura (DAS) em função da interação época e proporções

\begin{tabular}{ccc}
\hline Proporções & 86 DAS & Altura (m) \\
\hline $20 \% \mathrm{CR}+80 \% \mathrm{MI}$ & 118 DAS \\
$40 \% \mathrm{CR}+60 \% \mathrm{MI}$ & $1,75 \mathrm{aA}$ & $1,84 \mathrm{aA}$ \\
$60 \% \mathrm{CR}+40 \% \mathrm{MI}$ & $1,85 \mathrm{aA}$ & $2,12 \mathrm{aA}$ \\
$80 \% \mathrm{CR}+20 \% \mathrm{MI}$ & $1,62 \mathrm{aB}$ & $1,97 \mathrm{aA}$ \\
$100 \%$ MI & $1,71 \mathrm{aA}$ & $1,97 \mathrm{aA}$ \\
\hline Média & $1,72 \mathrm{aA}$ & $1,77 \mathrm{aA}$ \\
\hline
\end{tabular}

* Médias seguidas pela mesma letra minúscula na coluna e maiúscula na linha não diferem entre si pelo teste de Tukey a $5 \%$

A média de altura das plantas encontradas para o milheto neste trabalho foi inferior a evidenciada por Vazquez, Lema e Granzotto (2011) em um Argissolo Vermelho Amarelo Eutrófico em Fernandópolis/SP, atingindo 2,47 m. Apesar de a média de altura das plantas de milheto encontradas neste estudo aos 86 DAS $(1,75 \mathrm{~m})$ sejam menores se comparada a outros autores, quando avaliado em mesma época, os valores estão próximo aos descritos para essa espécie, que segundo a Embrapa (2018), atinge 1,80 m no florescimento. Já para aos 118 DAS $(1,92 \mathrm{~m})$ a altura encontrada foi próxima a relatada por outros autores como Teodoro et al. (2015) que obtiveram após a floração, quando os grãos apresentavam aspecto pastoso, 1,96 m.

Não houve diferença mínima significativa para a altura do milheto para a maioria das proporções quando comparada das épocas de avaliação, observando somente para a proporção 
de $60 \%$ CR + 20\% MI uma maior altura para o MI aos 118 DAS. Geraldo et al. (2002) em seu trabalho sobre fenologia e produção de biomassa seca e de grãos em cultivares de milheto observaram que, após a floração e a maturação do milheto, ocorreu o contínuo crescimento e acumulação de biomassa pela planta. Contudo, embora para o presente estudo, nas avaliações aos 118 DAS o MI já se encontrava em estágio de maturação fisiológica, o crescimento citado pelos autores não se mostrou muito evidente.

Houve efeito significativo entre as proporções de semeadura e épocas de avaliação (pvalor $=0,0001)$ para variável biomassa seca $(\mathrm{MS})$ da crotalária quando analisada de forma separada. Entre as proporções de semeadura avaliadas nas duas épocas de corte verificou-se aos 86 DAS, valores de MS variando de $602 \mathrm{~kg} \mathrm{ha}^{-1}$ para a proporção de semeadura de (20\% CR + $80 \%$ MI) a $3.531 \mathrm{~kg} \mathrm{ha}^{-1}$ quando em solteiro. Já aos 118 DAS os valores variaram de $1.250 \mathrm{~kg}$ $\mathrm{ha}^{-1}$ para a proporção de $20 \%$ a $7.420 \mathrm{~kg} \mathrm{ha}^{-1}$ para $100 \% \mathrm{CR}$. Para as proporções avaliadas dentro de cada época de corte, observou-se maior produtividade de biomassa seca aos 118 DAS (Figura 2).

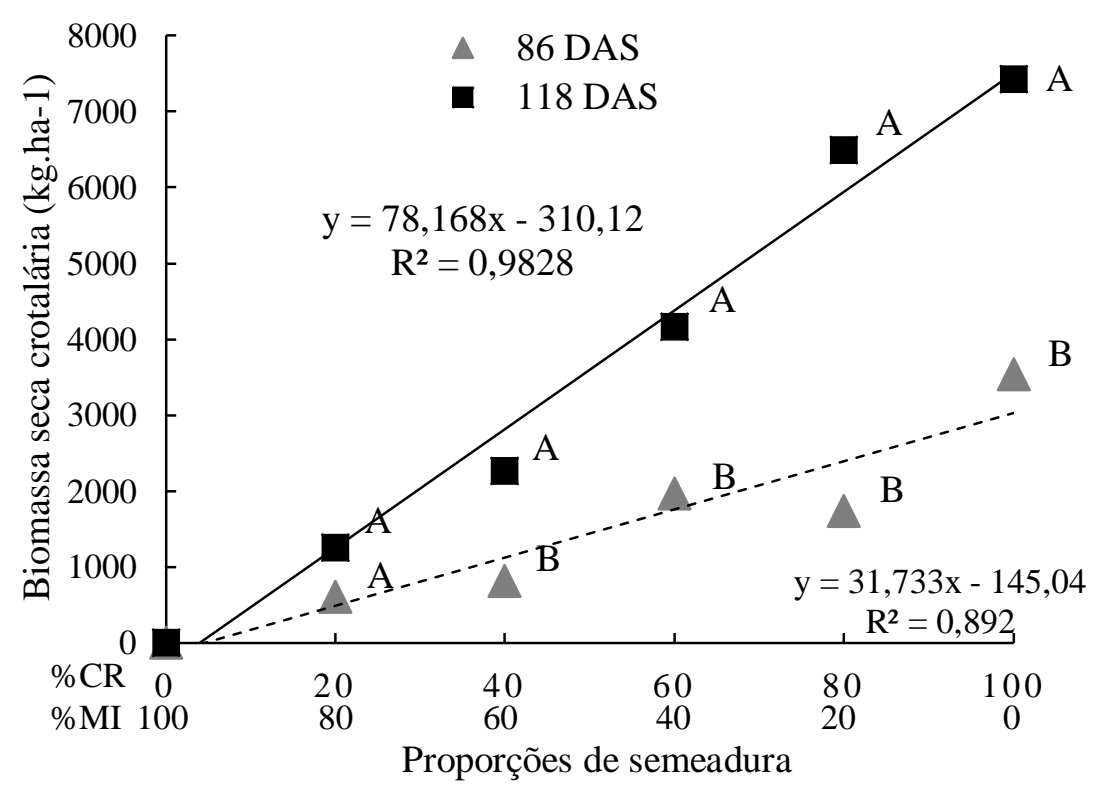

Figura 2 - Produtividades de biomassa seca da crotalária em relação as proporções de semeadura de crotalária

(\% CR) e milheto (\% MI) e produtividade da biomassa seca da crotalária aos 86 e 118 dias nas diferentes proporções de semeadura, em função da interação proporções e épocas.

* Médias seguidas pela mesa letra na mesma proporção em épocas diferentes não diferem entre si pelo teste de Tukey a $5 \%$

A produtividade de biomassa seca para crotalária cultivada em solteiro encontrada para esse estudo aos 86 DAS (3.531 $\left.\mathrm{kg} \mathrm{ha}^{-1}\right)$, foi superior ao encontrado por Cavalcante et al. (2012) que obtiveram $2.500 \mathrm{~kg} \mathrm{ha}^{-1}$ para essa leguminosa quando cultivada de maio a setembro em um Argissolo Vermelho Distrófico em Arapiraca/AL, com o corte realizado no momento florescimento (78 DAS). Aos 118 DAS a produtividade de massa seca da crotalária em solteiro 
(7.420 kg ha-1) foi semelhante ao encontrado por Gitti et al. (2012) que obtiveram também no florescimento, $7.850 \mathrm{~kg} \mathrm{ha}^{-1}$ de biomassa seca, quando cultivada durante a safra de verão em um Latossolo Vermelho Distrófico Álico no município de Servínia/MS. Para esses autores o potencial genético para produção de palhada durante aproximadamente 90 dias, quando cultivada no verão, juntamente com as raízes pivotantes das crotalárias são características de plantas com grande potencial de utilização em áreas de sistema de plantio direto, pois além de melhorias na estrutura física do solo, aporte de matéria orgânica, contribuem para elevar os teores de nitrogênio $(\mathrm{N})$ no solo. Já o aumento da produtividade da biomassa seca para a crotalária observada aos 118 DAS, assim como para massa verde, está relacionado ao estádio fenológico das plantas e, embora para alguns autores como Garcia e Staut (2018) a época de maior acúmulo de biomassa seca pelas crotalárias seja após o florescimento pleno e início da formação dos legumes; no presente estudo foi possível observar diferenças da produção de biomassa logo no início da floração quando comparado os 86 DAS.

Os resultados obtidos para produtividade de biomassa seca do milheto cultivado em solteiro (100\%) e quando em consórcio com a crotalária aos 86 e 118 DAS são representados na Figura 3 e na Tabela 4. Não foi verificada interação significativa para épocas e proporções de semeadura $(\mathrm{p}$-valor $=0,07)$, entretanto, foi significativo para essas variáveis de forma isolada (valor p para proporção menor que 0,001 e época 0,02 ). Entre as proporções, a produtividade de biomassa seca do milheto apresentou valores variando entre $896 \mathrm{~kg} \mathrm{ha}^{-1}$ para a proporção de semeadura de $80 \% \mathrm{CR}+20 \% \mathrm{MI}$ e $5.022 \mathrm{~kg} \mathrm{ha}^{-1}$ para o cultivo solteiro (100\% MI). Já entre as épocas de corte, observou-se que a maior média ocorreu aos 118 DAS.

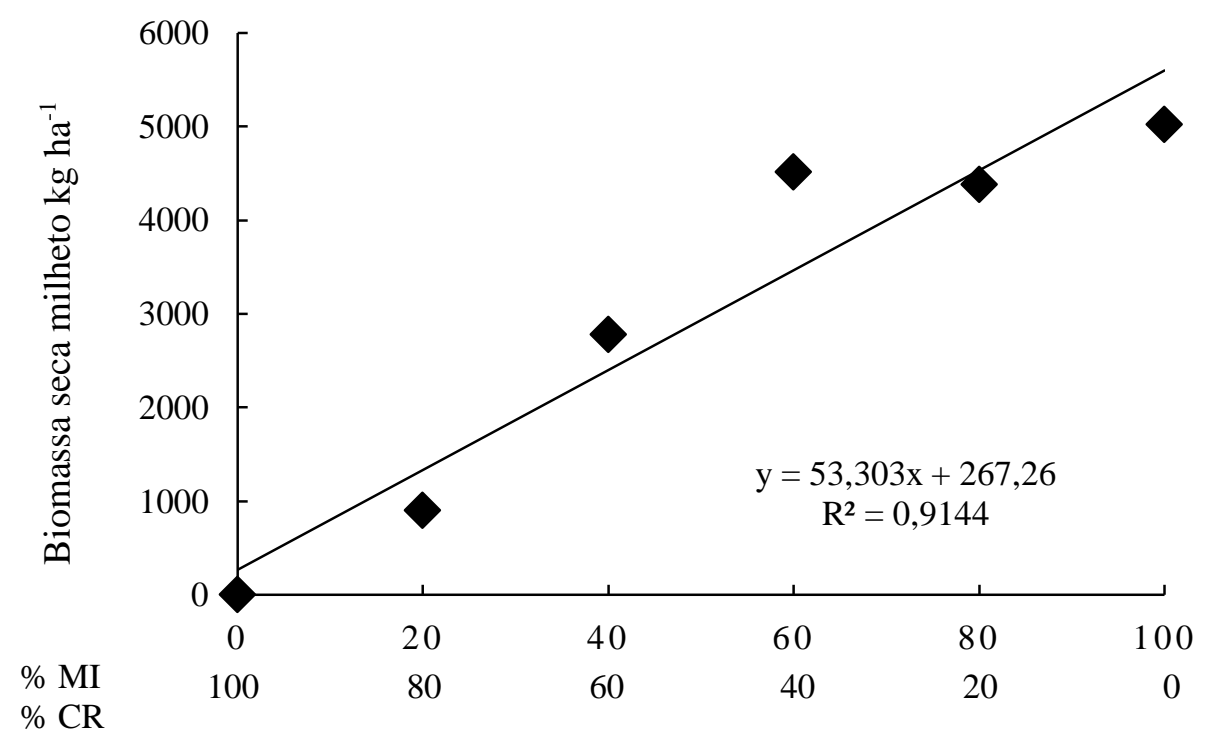

Proporções de semeadura

Figura 3 - Produtividades médias de biomassa seca do milheto em cada proporção de semeadura avaliadas aos 86 e 118 dias após a semeadura (DAS). 
Tabela 4 - Médias da produtividade de biomassa seca do milheto aos 86 e 118 dias após a semeadura (DAS)

\begin{tabular}{cc}
\hline Época $($ DAS $)$ & Biomassa Seca Milheto $\left(\mathbf{k g ~ h a}^{-\mathbf{1}}\right)$ \\
\hline 86 & $2.460 \mathrm{~b}$ \\
118 & $3.404 \mathrm{a}$ \\
\hline
\end{tabular}

*Médias seguidas pela mesma letra na coluna não diferem entre si pelo teste de Tukey a 5\%

A média da produtividade de massa seca do milheto em cultivo solteiro $\left(5.022 \mathrm{~kg} \mathrm{ha}^{-1}\right)$, foi inferior a obtida por Calvo, Foloni e Brancalião (2010) que obtiveram aos 90 DAS $5.585 \mathrm{~kg}$ $\mathrm{ha}^{-1}$ em um cultivo realizado nos meses de março a junho em um Argissolo Vermelho Distroférrico em Presidente Prudente/SP, Silva et al. (2010) que alcançaram $14.040 \mathrm{~kg} \mathrm{ha}{ }^{-1}$ durante o verão em um Nitossolo Vermelho em Botucatu/SP, Rodrigues et al. (2012) 12.600 $\mathrm{kg} \mathrm{ha}^{-1}$ aos 120 DAS durante a safra de verão em um Latossolo Vermelho Distrófico Típico Argiloso em Ilha Solteira/SP e superiores a obtida por Teixeira et al. (2008) que obtiveram aos 119 DAS, $2.907 \mathrm{~kg} \mathrm{ha}^{-1}$, no mesmo estágio fenológico do milheto neste trabalho aos 86 DAS e mesma localidade desse estudo, porém em épocas diferentes.

Embora o milheto aos 118 DAS encontrasse próximo a maturação fisiológica, foi possível observar o incremento de biomassa seca em relação aos 86 DAS. Carvalho et al. (2015), em seu trabalho sobre manejo de plantas de cobertura na floração e na maturação fisiológica e seu efeito na produtividade do milho, observaram um menor teor de biomassa seca para o milheto na maturação. Os autores atribuíram esse resultado à senescência da planta, à queda das folhas e à diminuição da produção pelo consumo dos grãos pelos pássaros. Para Padovan et al. (2011), o momento ideal para o manejo do milheto visando maior aporte de biomassa seca seria no momento do estádio fenológico de grãos leitosos e pastosos. Contudo, segundo Geraldo et al. (2002), embora o milheto BRS 1501 apresente menor duração da fase vegetativa, a planta possui perfilhos que em sua maioria acompanham o crescimento do colmo principal, alcançando um tamanho próximo a esse, garantindo assim, maior acúmulo de biomassa seca.

As médias da produtividade de biomassa seca total (proporções contento $\mathrm{CR}+\mathrm{MI}$, $100 \%$ CR e 100\% MI) dos tratamentos avaliados aos 86 e 118 DAS são apresentados na Figura 4 e Tabela 5. Não foi observada interação significativa para épocas e proporções (p- valor = $0,10)$, o mesmo ocorreu para as proporções quando avaliadas de forma isolada ( $p$ - valor $=0,85$ ). Contudo, foram verificadas diferenças significativas entre as épocas de avaliação (p-valor = 0,01). Dentre as proporções estudadas obteve-se valores entre $5.022 \mathrm{~kg} \mathrm{ha}^{-1}$ para o milheto em cultivo solteiro $(100 \% \mathrm{MI})$ e $6.057 \mathrm{~kg} \mathrm{ha}^{-1}$ para o consórcio de $40 \% \mathrm{CR}+60 \% \mathrm{MI}$ (Figura 4 ). 
Dentre as épocas de avaliação o maior acúmulo de biomassa seca foi observado aos 118 DAS (Tabela 5).

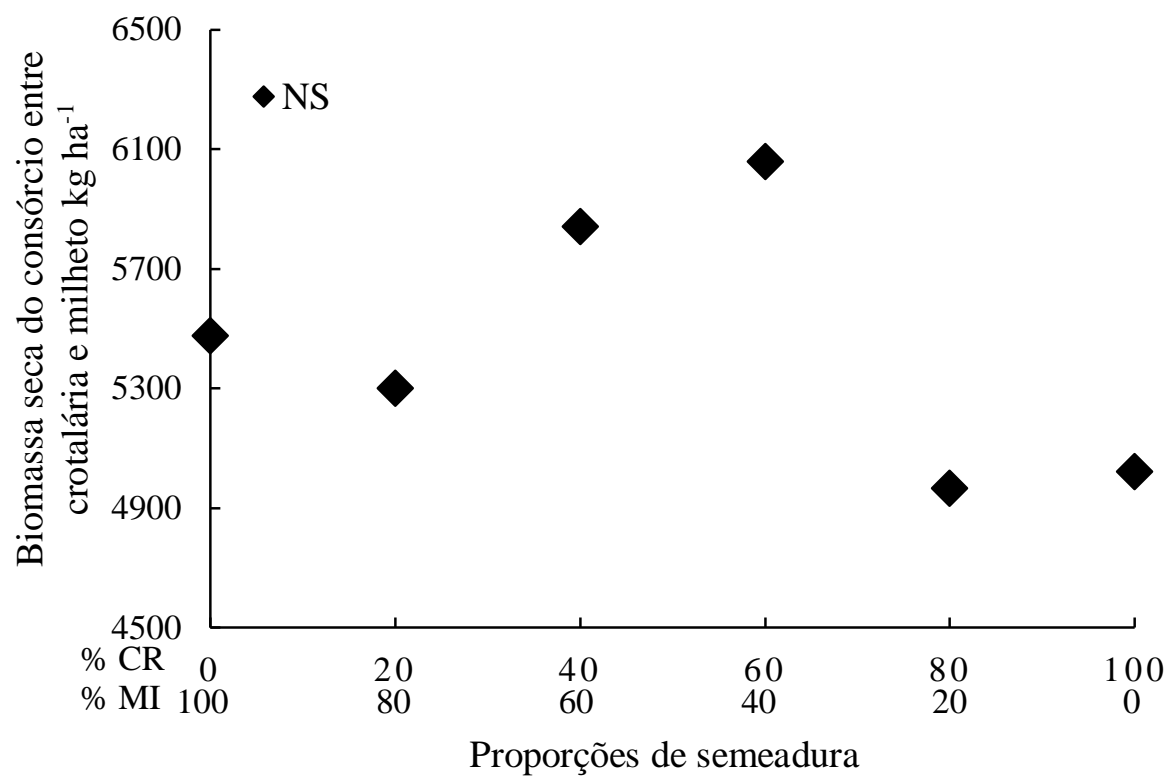

Figura 4 - Produtividades médias totais de biomassa seca do consórcio contendo crotalária (CR) e milheto (MI) em cada proporção de semeadura avaliadas aos 86 e 118 dias após a semeadura (DAS)

Tabela 5 - Média da produtividade de biomassa seca total (proporções contendo CR + MI, 100\% MI e 100\% CR) avaliados aos 86 e 118 dias após a semeadura (DAS)

\begin{tabular}{cc}
\hline Época (DAS) & Biomassa Seca Total $\left(\mathbf{k g ~ h a}{ }^{-1}\right)$ \\
\hline 86 & $3.901 \mathrm{~b}$ \\
118 & $7.002 \mathrm{a}$ \\
\hline
\end{tabular}

* Médias seguidas pela mesma letra não diferem entre sí pelo teste de Tukey a 5\%

As médias da produtividade total de biomassa seca nos consórcios contendo CR + MI obtidas neste trabalho $\left(5.299 \mathrm{a} 6.057 \mathrm{~kg} \mathrm{ha}^{-1}\right)$ foram inferiores às encontradas por outros autores. Rodrigues et al. (2012) encontraram valores superiores em consórcios constituídos por gramíneas e leguminosas aos 120 DAS, dentre eles o consórcio contendo mucuna (Stizolobium aterrimum $)+$ milheto $\left(23.300 \mathrm{~kg}\right.$ ha-1), crotalária + milheto $\left(14.800 \mathrm{~kg} \mathrm{ha}^{-1}\right)$ e guandu (Cajanus cajan $)+$ milheto $\left(12.100 \mathrm{~kg} \mathrm{ha}^{-1}\right)$ quando cultivados no verão em um Latossolo Vermelho Distrófico Típico em Ilha Solteira/SP. Os autores concluem ainda que obtiveram maiores acúmulos de biomassa seca em todos os consórcios contendo milheto.

$\mathrm{Na}$ Tabela 5 onde estão apresentadas as médias da produtividade de biomassa seca total (proporções de CR + MI, 100\% MI e 100\% CR) aos 86 e 118 DAS, observou-se o aumento da biomassa seca aos 118 DAS. Para Gomes, Vernetti Júnior e Silveira (1998), quando comparada a leguminosas, as gramíneas produzem maior quantidade de fitomassa, fator que está 
relacionado ao rápido desenvolvimento inicial e melhor adaptação as adversidades climáticas. Contudo, para o presente trabalho, essa diferença entre gramíneas em relação as leguminosas não foram observadas, mostrando um comportamento semelhante do milheto e crotalária na produção final de massa seca. Esse fato pode ser observado na Figura 4, em que não foram observadas diferenças significativas na produtividade de biomassa seca total entre as proporções constituídas de CR + MI e seus cultivos em solteiro (100\% CR e 100\% MI). Isso evidencia que o emprego do consórcio contendo $\mathrm{CR}+\mathrm{MI}$ não reduziu a produtividade total de massa em relação ao cultivo isolado de milheto e crotalária, indicando assim, bom potencial para utilização.

De acordo com Alvarenga et al. (2001), são necessárias 6 ton. ha ${ }^{-1}$ de palhada para que se realize uma taxa adequada de cobertura do solo para o sistema de plantio direto. Portanto, para esse trabalho, tendo em vista a média geral dos tratamentos em segunda época de corte, o valor de produtividade de biomassa seca aos 118 DAS está acima do valor necessário, evidenciando assim, a eficiência do consórcio entre gramínea e leguminosa no aporte de palhada.

Após o manejo das plantas de cobertura, a duração da palhada na superfície do solo é determinada pela velocidade de decomposição de seus resíduos; portanto, se a decomposição da palhada for rápida, os nutrientes serão liberados nessa mesma velocidade e com isso uma menor proteção será oferecida ao solo (HEINRICHS et al., 2001). Dessa forma, o consórcio entre plantas de cobertura deve fornecer proteção ao solo, adicionar nitrogênio e proporcionar uma biomassa seca com relação $\mathrm{C} / \mathrm{N}$ intermediária àquelas das espécies em cultivo solteiro. Uma biomassa seca com relação $\mathrm{C} / \mathrm{N}$ intermediária resulta em uma taxa de decomposição menor que observado em leguminosas, possibilitando a cobertura do solo por mais tempo, promovendo sincronia entre a liberação de nitrogênio e a demanda pelas culturas comerciais (GIACOMINI et al., 2013). Assim, devido aos benefícios mencionados, se torna vantajoso a formação de palhada proveniente do consórcio entre gramíneas e leguminosas como os estudados neste trabalho.

O desempenho dos consórcios avaliados neste experimento pode ser melhor compreendido pela interpretação da Tabela 6, em que é possível observar que para todos as proporções testadas obteve-se o Índice de Equivalência de Área (IEA) maior que um (1). Evidencia-se, assim, que nas proporções de consórcio estudadas neste trabalho, há uma vantagem de aproveitamento da área na associação crotalária e milheto. Ou seja, existe um efeito positivo na produtividade quando se utiliza o consórcio, ocasionando uma produção complementar quando comparado aos cultivos solteiros de MI e CR. 
Tabela 6 - Índices agronômicos para a produtividade dos consórcios constituídos de crotalária (CR) e milheto (MI) colhidos aos 118 dias após a semeadura (DAS)

\begin{tabular}{cccccccc}
\hline \multirow{2}{*}{ Proporções } & \multicolumn{3}{c}{ Crotalária } & \multicolumn{3}{c}{ Milheto } & \multirow{2}{*}{ IEA } \\
\cline { 2 - 7 } & $\mathbf{I}_{\mathbf{C R}}$ & $\mathbf{E R P}_{\mathbf{C R}}$ & $\mathbf{C R C}_{\mathbf{C R}}$ & $\mathbf{I}_{\mathbf{M I}}$ & $\mathbf{E R P}_{\mathbf{M I}}$ & $\mathbf{C R C}_{\mathbf{M I}}$ & \\
\hline $80 \% \mathrm{CR}+20 \% \mathrm{MI}$ & 0,87 & 1,08 & $81,10 \%$ & 0,20 & 1,01 & $18,90 \%$ & 1,07 \\
$60 \% \mathrm{CR}+40 \% \mathrm{MI}$ & 0,56 & 0,93 & $49,71 \%$ & 0,56 & 1,41 & $50,29 \%$ & 1,12 \\
$40 \% \mathrm{CR}+60 \% \mathrm{MI}$ & 0,30 & 0,76 & $29,34 \%$ & 0,73 & 1,21 & $70,66 \%$ & 1,03 \\
$20 \% \mathrm{CR}+80 \%$ MI & 0,27 & 1,33 & $23,58 \%$ & 0,86 & 1,08 & $76,42 \%$ & 1,13 \\
\hline
\end{tabular}

$\mathrm{I}_{\mathrm{MI}}=$ Uso eficiente de terra parcial para o milheto; $\mathrm{I}_{\mathrm{CR}}=$ Uso eficiente de terra parcial para a crotalária; $\mathrm{ERP}_{\mathrm{MI}}=$ Eficiência parcial para o milheto; $\mathrm{ERP}_{\mathrm{CR}}=$ Eficiência parcial para a crotalária; $\mathrm{CRC}_{\mathrm{MI}}=$ Contribuição relativa do milheto ao IEA; $\mathrm{CRC}_{\mathrm{CR}}=$ Contribuição relativa da crotalária ao IEA; IEA = Uso e eficiência da terra ou índice de equivalência de área

Os Índices de uso eficiente de terra parcial ( $\mathrm{I}_{\mathrm{CR}}$ e $\mathrm{I}_{\mathrm{MI}}$ ) mostraram que, para o milheto existem ganhos em todas as proporções em consórcio, no entanto para a crotalária as combinações $40 \% \mathrm{CR}+60 \% \mathrm{MI}$ e $60 \% \mathrm{CR}+40 \%$ MI que obtiveram $\mathrm{I}_{\mathrm{CR}}$ menor que a proporção de crotalária na população, não obtiveram ganhos. Nos demais casos verificaram-se então, ganhos agronômicos para ambas as plantas de cobertura utilizadas no consórcio.

A contribuição relativa das culturas (CRC) representa a participação de cada cultura no Índice de Eficiência de Área (IEA), para as combinações avaliadas. Para o milheto o consórcio parece ter sido mais efetivo. Observa-se que para os consórcios $40 \% \mathrm{CR}+60 \% \mathrm{MI}$ e $60 \% \mathrm{CR}+$ $40 \%$ MI, o $\mathrm{CRC}_{\mathrm{MI}}(\%)$ do milheto foi superior a sua participação na população e consequentemente, o $\mathrm{CRC}_{\mathrm{CR}}(\%)$ da $\mathrm{CR}$ menor que a participação dessa cultura na população inicial para esse mesmo consórcio. Contudo, para o consórcio $20 \% \mathrm{CR}+80 \% \mathrm{MI}$ e $80 \% \mathrm{CR}$ e $20 \%$ MI o $\mathrm{CRC}_{\mathrm{CR}}(\%)$ da $\mathrm{CR}$ é superior que sua participação na população e o $\mathrm{CRC}_{\mathrm{MI}}(\%)$ do MI inferior.

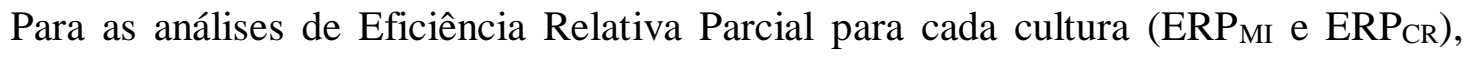
mostrou uma vantagem parcial em termos de produtividade para o MI em todas as combinações de consórcio, sendo o consórcio $60 \% \mathrm{CR}+40 \%$ MI que obteve maior índice $(1,41)$. Já para a CR, somente os consórcios $20 \% \mathrm{CR}+80 \% \mathrm{MI}$ e $80 \% \mathrm{CR}+20 \%$ MI obtiveram índices maiores que 1. Portanto, isso evidencia que a produtividade agronômica da CR com ganhos de 33\% seria no consórcio $20 \%$ CR $+80 \%$ MI e, para o MI, com ganhos de $41 \%$ seria no consórcio $60 \%$ CR + 40\% MI. Contudo, de acordo com os IEAs obtidos a partir do presente estudo, observa-se que o consórcio é de maneira geral vantajoso em relação ao cultivo solteiro variando de 3 a 13\%. Porém, as melhores escolhas seriam para o consórcio que obteve maior IEA, ou seja, $20 \% \mathrm{CR}+80 \% \mathrm{MI}$. 


\section{CONCLUSÃO}

O cultivo consorciado de milheto e crotalária não reduz a produção total de biomassa em relação aos seus respectivos monocultivos (100\% crotalária e $100 \%$ milheto).

O manejo realizado aos 118 dias proporciona a quantidade de biomassa adequada para os sistemas de produção de grãos para o município de Lavras/MG.

Todos os consórcios utilizados promovem ganhos em relação ao cultivo solteiro, contudo, o maior índice de eficiência de área (IEA) é evidenciado no consórcio constituído por $20 \%$ de crotalária e $80 \%$ de milheto.

\section{REFERÊNCIAS}

ALVARENGA, R. C. et al. Plantas de cobertura do solo para sistema de plantio direto. Informe Agropecuário, Belo Horizonte, v. 22, n. 208, p. 25-36, 2001.

BARRETO, A. C.; FERNANDES, M. F. Recomendações técnicas para o uso da adubação verde em solos de tabuleiros costeiros. Circular Técnica 19, Embrapa Tabuleiros Costeiros, Aracajú, 2001.

BEZERRA, C. A. et al. Rendimento, componentes da produção e uso eficiente da terra nos consórcios sorgo x feijão-de-porco e sorgo x milho. Revisa Ciência Agronômica, Fortaleza, v. 38, n. 1, p. 104-108, 2007.

BOER, C. A. et al. Biomassa, decomposição e cobertura do solo ocasionada por resíduos culturais de três espécies vegetais na região centro-oeste do Brasil. Revista Brasileira de Ciência do Solo, Viçosa, v. 32, n. 2, p. 843-851, 2008.

BRASIL. Ministério da Agricultura. Departamento Nacional de Meteorologia. Normas climatológicas 1961-1990. Brasília, 1992.

CALVO, L. C.; FOLONI, J. S. S.; BRANCALHÃO, S. R. Produtividade de fitomassa e relação $\mathrm{C} / \mathrm{N}$ de monocultivos e consórcios de guandú-anão, milheto e sorgo em diferentes épocas de corte. Revista Bragantia, Campinas, v. 69, n. 1, p. 77-86, 2010.

CARVALHO, A. M. et al. Desempenho agronômico de plantas de cobertura usadas na proteção do solo no período de pousio. Pesquisa Agropecuária Brasileira, Brasília, v. 48, n. 2, p. 157-166, 2013.

CARVALHO, A. M. et al. Manejo de plantas de cobertura na floração e na maturação fisiológica e seu efeito na produtividade do milho. Revista Pesquisa Agropecuária Brasileira, Brasília, v.5 0, n. 7, p. 551-561, 2015.

CAVALCANTE, V. S. et al. Biomassa e extração de nutrientes por plantas de cobertura. Revista Brasileira de Engenharia Agrícola e Ambiental, Campina Grande, v. 16, n. 5, p. 521-528, 2012. 
CHERR, C. M.; SCHOLBERG, J. M. S.; MCSORLEY, R. Green manure approaches to crop production: a synthesis. Agronomy Journal, Madison, WI, v.98, n. 2, p.302-319, 2006.

DANTAS, A. A. A.; CARVALHO, L. G. de; FERREIRA, E. Classificação e tendência climática em Lavras, MG. Ciência e Agrotecnologia, Lavras, v. 31, n. 6, p. 1862-1866, 2007.

EMPRESA BRASILEIRA DE PESQUISA AGROPECUÁRIA. Sistema brasileiro de classificação de solos. Brasília, 1999.

EMPRESA BRASILEIRA DE PESQUISA AGROPE. Sistema de produção Embrapa. Cultivo do milheto. Brasília, 2018. Disponível em:

https://www.spo.cnptia.embrapa.br/conteudo?p p id=conteudoportlet WAR sistemasdeprod ucaolf6_1ga1ceportlet\&p_p_lifecycle $=0 \& p \_p \_s t a t e=$ normal\&p_p_mode $=$ view $\& p \_p \_c o l \_i d=$ column-1\&p_p_col_count $=1 \& p \_r \_p \_-76293187 \_$sistemaProducaoId $=8101 \& p \_r \_p \_-$ 996514994_topicoId=1309. Acesso em: 23 nov. 2018.

FERRARI NETO, J. et al. Plantas de cobertura, manejo da palhada e produtividade da mamoneira no sistema de plantio direto. Revista Ciência Agronômica, Fortaleza, v. 42, n. 4, p. 978-985, 2011.

FERREIRA, D. F. Sisvar: a computer statistical analysis system. Ciência e Agrotecnologia, Lavras, v. 35, n.6, p. 1039-1042, 2011.

GARCIA, R. A.; STAUT, L. A. Como inserir crotalária em sistemas de produção de grãos. Circular Técnica 44, Embrapa Agropecuária Oeste, Dourados, dez. 2018.

GERALDO, J. et al. Fenologia de produção de massa seca de grãos em cultivares de milhetopérola. Revista Pesquisa Agropecuária Brasileira, Brasília, v. 37, n. 9, p. 1263-1268, 2002.

GIACOMINI, S. J. et al. Matéria seca, relação C/N e acúmulo de nitrogênio, fósforo e potássio em misturas de plantas de cobertura de solo. Revista Brasileira de Ciência do Solo, Viçosa, v. 27, n. 2, p. 325-334, 2013.

GITTI, D. de C. et al. Épocas de semeadura de crotalária em consórcio com o milho. Revista Brasileira de Milho e Sorgo, Sete Lagoas, v. 11, n. 2, p. 156-168, 2012.

GOMES, A. S.; VERNETTI JÚNIOR, F. J.; SILVEIRA, L. D. N. Rendimento de milho e soja cultivados no sistema plantio direto, sob diferentes coberturas mortas, em um solo de várzea. Comunicado Técnico 9, Embrapa Clima Temperado, Pelotas, 1998.

HEINRICHS, R. et al. Cultivo consorciados de aveia e ervilhaca: relação C/N da fitomassa e produtividade do milho em sucessão. Revista Brasileira de Ciência do Solo, Viçosa, v. 25, n. 2, p. 331-340, 2001.

LIEBMAN, M. Sistemas de policultivos. In: ALTIERI, M. Agroecologia: bases científicas para uma agricultura sustentável. 3. ed. São Paulo/Rio de Janeiro: Expressão Popular, 2012. p. 221-240.

MARCATE, N. C.; CAMACHO, M. A.; PAREDES, F. P. Teores de nutrientes no milheto como cobertura de solo. Bioscience Journal, Uberlândia, v. 27, n. 2, p. 196-204, 2011. 
MATEUS, G. P; WUTKE, E. B. Espécies de leguminosas utilizadas como adubos verdes. Revista Pesquisa \& Tecnologia, Campinas, v. 3, n. 1, p. 1-15, 2006.

PADOVAN, M. P. et al. Estágio mais adequado de manejo do milheto para fins de adubação verde. Comunicado técnico 171, Embrapa Agropecuária Oeste, Dourados, 2011.

PERIN, A. et al. Acúmulo e liberação de P, K, Ca e Mg em crotalária e milheto solteiros e consorciados. Revista Ceres, Viçosa, v. 57, n. 2, p. 274-281, 2010.

RODRIGUES, G. B. et al. Matéria e nutrientes da parte aérea de adubos verdes em cultivos exclusivo e consorciado. Revista Ceres, Viçosa, v. 59, n. 3, p. 380-385, 2012.

RÓS, A. B.; SÃO JOÃO, R. E. Desempenho agronômico e uso eficiente da terra em arranjos de plantas de mandioca e batata-doce. Revista Ceres, Viçosa, v. 63, n. 4, p. 517-522, 2016.

SILVA, A. G. et al. Produção de fitomassa e acúmulo de nutrientes por plantas de cobertura e cultivo da mamona em sucessão no sistema de plantio direto. Revista Ciência Rural, Santa Maria, v. 40, n. 10, p. 2092-2098, 2010.

SOARES, C. M. J. et al. Produção de adubos verdes no cerrado e seus efeitos sobre as plantas daninhas. Revista de Ciências Agroambientais, Alta Floresta, v. 13, n. 2, p. 57-64, 2015.

SOUZA, J. O.; MACEDO, M. A. S. Análise da viabilidade econômica de sistemas orgânicos de produção consorciada. Associação Brasileira de Custos, São Leopoldo, v. 2, n. 1, p. 6082, p. 60-82, 2007.

TEIXEIRA, C. M. et al. Fitomassa, teor e acúmulo de micronutrientes do milheto, feijão-deporco e guandú-anão, em cultivo solteiro e consorciado. Revista Acta Scientiarum.

Agronomy, Maringá, v. 30, n. 4, p. 553-538, 2008.

TEODORO, R. B. et al. Aspectos agronômicos de leguminosa para adubação verde no cerrado do Alto Vale do Jequitinhonha. Revista Brasileira de Ciência do Solo, Viçosa, v. 35 , n. 2, p. 635-643, 2011.

TEODORO, P. E. et al. Preparação do solo e da adubação azota nos componentes produtivos do milheto. Revista Ciências Agrárias, Lisboa, v. 38, n. 3, p. 305-309, 2015.

VAZQUEZ, G. H.; LEMA, A. C. F.; GRANZOTTO, R. Produção de fitomassa seca de oito espécies vegetais em duas épocas de semeadura na região noroeste do estado de São Paulo.

Revista Nucleus: Revista Científica da Fundação Educacional de Ituverava, Ituverava, v. 8, n. 1, p. 1-16, 2011.

WILLEY, R.W. Intercropping: its importance and research needs. Part 1. Competition and yield advantages. Field Crops Abstracts, Hurley, v. 32, n. 1, p. 1-10, 1979.

\section{DADOS DOS AUTORES:}

Karina Mendes Bertolino

E-mail: karina.bertolino@yahoo.com.br

Curriculum Lattes: http://lattes.cnpq.br/4879536941988300 
Doutoranda e mestrado em Fitotecnia pela Universidade Federal de Lavras e graduação em Engenharia Agronômica e Bacharelado Interdisciplinar em Biossistemas pela Universidade Federal de São João Del-Rei.

\section{Giuliana Rayane Barbosa Duarte}

E-mail: giuliana_duarte@yahoo.com.br

Curriculum Lattes: http://lattes.cnpq.br/4063782409496857

Mestre em Agronomia/Fitotecnia pela Universidade Federal de Lavras (UFLA), Graduação em Agronomia pela UFLA e Universidad Nacional de La Plata, Técnica em Agropecuária. Atualmente é servidora pública (Técnico em Agropecuária) na Universidade Federal de Lavras. Tem experiência na área de Melhoramento Genético de Olerícolas, com ênfase em alface e feijão vagem.

\section{Gustavo Maldini Penna de Valadares e Vasconcelos}

E-mail: gustavomaldini@hotmail.com

Curriculum Lattes: http://lattes.cnpq.br/8568026446196324

Mestrando em Fitotecnia na Universidade Federal de Lavras e graduação em Engenharia Agronômica e Bacharelado Interdisciplinar em Biossistemas pela Universidade Federal de São João Del-Rei.

\section{Élberis Pereira Botrel}

E-mail: elberis@ufla.br

Curriculum Lattes: http://lattes.cnpq.br/6996830597561413

Doutorado, mestrado e graduação em Agronomia pela Universidade Federal de Lavras. Atualmente é Professor Associado II na Universidade Federal de Lavras. Exerceu as funções de Chefe do Departamento de Agricultura, Pró-Reitor de Assuntos Estudantis e Comunitários, Chefe de Gabinete, Prefeito Universitário e Assessor de Comunicação Social. Tem experiência na área de Agronomia, com ênfase em manejo e tratos culturais, atuando principalmente nos seguintes temas: plantio direto, adubação verde, plantas de cobertura, manejo de resíduos, agroenergia, café, soja, mandioca e olerícolas. 